\title{
Adenosine triphosphate bioluminescence for hygiene testing of rubber liners and tubes on dairy farms
}

\author{
Ida Clemensson Lindell,, Åse Lundh, ${ }^{* 1}$ Kerstin Svennersten Sjaunja, $†$ and Marika Cederholm $\ddagger$ \\ ${ }^{*}$ Department of Molecular Sciences, Swedish University of Agricultural Sciences, PO Box 7015, SE-750 07 Uppsala, Sweden \\ †Department of Animal Nutrition and Management, Swedish University of Agricultural Sciences, PO Box 7024, SE-750 07 Uppsala, Sweden \\ ‡DeLaval International, PO Box 39, SE-147 21 Tumba, Sweden
}

\begin{abstract}
Prevention of biofilm formation in milking equipment is important to ensure good hygiene quality of raw milk. Key factors to achieving good results are a successful cleaning procedure and a method to check the cleanliness of milking equipment surfaces. Adenosine triphosphate bioluminescence is a fast and easy method for investigating bacterial contamination of surfaces. However, previous studies on the potential of ATP bioluminescence to assess the hygiene status of milking equipment have been hampered by lack of a validated test procedure. The aim of this work was therefore to establish a test procedure for assessing the cleanliness of milking equipment using ATP bioluminescence, and apply the method on-farm to study the hygiene status of aging rubber material in milking equipment. In developing the test procedure, the effects of sampling location in tubes and liners, sampling of dry versus wet barrels, milking point in the parlor, and acid or alkali detergent on ATP values were investigated. The results showed that, to obtain reproducible results, replicate sampling from the same milking points in the parlor is important. For milk tubes, samples should preferably be taken from the milk meter side, for liners on the inside of the barrel. For best results, sampling should be performed after use of alkali detergent. No beneficial effect was observed of sampling dry liner barrels, so sampling in the standardized test procedure is performed directly after cleaning. The standardized test procedure was used on 3 different commercial farms and sampling was initiated after replacement of old rubber parts. On one of the farms, additional sampling was performed to evaluate total bacteria count and determine the association with ATP level. The results suggest that, provided an efficient clean-
\end{abstract}

Received July 10, 2017.

Accepted November 13, 2017.

${ }^{1}$ Corresponding author: ase.lundh@slu.se ing procedure is used, the hygiene quality of milking equipment can be maintained during the recommended lifetime of the rubberware. However, due to occasional variation in cleaning efficiency between milking points and liner barrels, random sampling on single occasions can lead to incorrect conclusions. Replicate sampling over time is therefore important for correct interpretation of ATP bioluminescence data. If ATP levels are very high, complementary sampling for total bacteria count should be used to verify that the level is due to bacterial contamination, and not other organic ATPcontributing material (e.g., milk residues).

Key words: milking equipment, ageing rubber material, standardized test procedure, field study

\section{INTRODUCTION}

Biofilm formation by bacteria in milking equipment is an important source of contamination of bulk tank milk (Elmoslemany et al., 2009; Verdier-Metz et al., 2009; Bava et al., 2011). To ensure good hygiene quality of raw milk, measures are required to prevent biofilm formation (Latorre et al., 2010). Factors contributing to biofilm formation in milking equipment include insufficient cleaning and hygiene, and aging of rubber material (Hillerton et al., 2004; Teixeira et al., 2005). As teat cup liners age, the chemical composition of the rubber material changes and therefore rubber liners usually have a recommended maximum life of 2,500 milkings. In studies by Hillerton et al. (2004) and Boast et al. (2008), it was found that liners aged for approximately 1,500 and 4,000 milkings, respectively, had an increased number of cracks and deposits of organic and inorganic material on the inner surface. Similar findings have been reported by Storgards et al. (1999), who studied aging rubber material in a dairy processing environment.

Efficient cleaning can reduce the risk of bacteria accumulating and forming a biofilm between milkings, and the clean-in-place (CIP) procedure is commonly used in different milking systems. Four major factors 
contribute to the success of CIP in a milking system: (1) the thermal factor, determined by the temperature of the water; (2) the chemical factor, determined by the type and dose of detergent; (3) the time factor, determined by the length of the washing procedure; and (4) the physical factor, determined by the amount and turbulence of the water in the milking system (Reinemann et al., 2003; Teh et al., 2014). To ensure good hygiene quality of milk delivered to dairies, it is desirable to have reliable methods to assess the results of the on-farm cleaning procedure and the cleanliness of milking equipment surfaces.

Adenosine triphosphate bioluminescence has been shown to be a fast and easy method for investigating bacterial contamination of surfaces and assessing the efficiency of cleaning (Shama and Malik, 2013). The method is based on a reaction between ATP molecules and the enzyme luciferase with its substrate luciferin (Griffiths, 1993). In this reaction, ATP is converted to AMP with the emission of light at an intensity that is directly proportional to the amount of ATP in the sample (Shama and Malik, 2013). The method indirectly measures the number of microorganisms in a sample and results are obtained within minutes. The technique can be effectively used under field conditions but should be combined with microbiological testing because other nonbacterial organic material can also contribute ATP (Corbitt et al., 2000; Aycicek et al., 2006; Shama and Malik, 2013).

Previous studies using ATP bioluminescence to assess microbial contamination of milking equipment have been hampered by lack of a validated test procedure for measurements of ATP levels. Moreover, descriptions of the test procedures used in previous studies are incomplete, and large variations between measurements on individual farms and between farms have been reported (Slaghuis and Wiegersma, 1996; Reinemann and Ruegg, 2000; Vilar et al., 2008). The correlation between ATP level and total bacteria count (TBC) in milking equipment has also shown varying results in previous studies, from no correlation (Meyer and Schmidt, 1997) to a coefficient of determination $\left(\mathrm{R}^{2}\right)$ of 0.73 (Reinemann and Ruegg, 2000). Therefore, when using ATP bioluminescence, a reliable sampling procedure is needed that allows for correct interpretation of ATP readings and leads to better conclusions regarding the hygiene status of milking equipment.

The aims of this study were thus to (1) establish and evaluate a test procedure for hygiene testing of rubber liners and tubes using ATP bioluminescence and (2) apply the test procedure in the field to investigate deterioration of the hygiene status of aging rubber liners and tubes.

\section{MATERIALS AND METHODS}

\section{Experimental Design}

Three commercial dairy farms participated in the study that was conducted in 2 parts. In the method development part, ATP bioluminescence was used to establish and verify a test procedure for hygiene testing of rubber liners and tubes on the farm level. Criteria in developing the test procedure were that it could be used on farms without damaging of milking equipment, that the values obtained were representative of the general hygiene status of the equipment and that the method had high reproducibility. The test procedure was developed on one of the case farms (farm A) by investigating the effect on ATP level of 4 different parameters of relevance for field testing. Case farms and the different parameters are described further below.

In on-farm studies, the test procedure developed was then applied to investigate deterioration of the hygiene status of aging rubber liners and tubes. Newly installed milking equipment was sampled once a month on 3 farms, at intervals of 21 to $35 \mathrm{~d}$. The variation in sampling interval was caused by practical circumstances on the farms. The manufacturers recommendation for using liners is up to 2,500 milkings or $6 \mathrm{mo}$, whatever comes first (DeLaval, Tumba, Sweden). Because sampling continued for 6 mo on all farms in the study, the liners were used for at most 4,050 milkings. In addition, the correlation between ATP readings and TBC was evaluated on one farm.

\section{Establishment of Test Procedure}

The 4 parameters investigated in development of the test procedure were (1) sampling location on the inside of liner and tube, (2) sampling of dry versus wet liner barrels, (3) milking point in the parlor, and (4) type of detergent. One parameter at a time was varied while the others were kept constant. The effect of sampling location on liners was tested by swabbing 3 different surface areas inside the liner: the lip (approximately $16.5 \mathrm{~cm}^{2}$ ), the head (approximately $35 \mathrm{~cm}^{2}$ ), and the barrel (approximately $80 \mathrm{~cm}^{2}$ ). On milk tubes, swabs were taken inside the tube at both ends (approximately $2-15 \mathrm{~cm}$ into the tube, $60 \mathrm{~cm}^{2}$ ). To investigate the effect of sampling dry versus wet liners, all liners of a cluster were dried for $4 \mathrm{~h}$ before swabbing. Drying was performed by removing liners from the jetter after cleaning and allowing them to air dry in a vertical position with the lip facing downward. The resulting ATP readings were then compared with those taken immediately after the cleaning procedure. The effect of milking point location 
in the parlor was studied by sampling one liner of a cluster at each milking point and comparing the results for opposite sides of the parlor. Finally, samples were taken from liners after use of a commercial acid, or alkali detergent (Mepa Acid NP free, pH 1.0 and Mepa CIP NP free, pH 12.1-12.7, Ecolab, Älvsjö, Sweden), and the results were compared. For each parameter, 4 to 11 samples were taken from different liners and tubes located at the same or adjacent milking points. The number of samples taken varied based on practical circumstances. When samples showed high variation in RLU values and appeared contaminated with unexpectedly high RLU values, additional samples were taken to be able to interpret the results.

\section{Application of Test Procedure in Field}

In the field study, the standardized test procedure was applied on 3 commercial farms for sampling of newly replaced rubber parts. On each sampling occasion, ATP measurements were also performed on the water used for cleaning to ensure that the water quality did not affect the ATP readings. The ambient temperature in the barn was recorded. Samples were not taken if the return temperature of the water used for cleaning was below $42^{\circ} \mathrm{C}$, or if the cleaning procedure had failed in any other way. The milk meter was used as an additional control point and was considered to be the best location to detect failure of the cleaning procedure. The material in the milk meter is inert and easy to clean, and is usually not contaminated by external dirt (A-L. Hörberg, DeLaval, Tumba, Sweden, personal communication). To study the correlation between ATP level and TBC, adjacent areas on 2 liner barrels of the same cluster were swabbed for both ATP and TBC during the whole trial period on one of the farms.

\section{Case Farms}

Three Swedish dairy farms with milking parlors participated in the study, which was carried out from April to October 2014. The farms (A-C) were chosen based on type of milking system and equipment and were similar with respect to number of cows and milking frequency. All farms were located in the same geographical area, close to Stockholm, Sweden.

Farm A was a conventional farm that milked approximately 100 cows twice a day in a milking parlor with $2 \times 8$ milking points. Farm $B$ was an organic farm that milked approximately 100 cows in a milking parlor with $2 \times 4$ milking points. Farm $\mathrm{C}$ was also an organic farm that milked approximately 160 cows twice a day in a milking parlor with $2 \times 8$ milking points. All 3 farms used DeLaval original rubber liners. Farms A and B also used DeLaval original rubber tubes, whereas farm $\mathrm{C}$ used silicone tubes that were not assessed in the study. On all 3 farms, a CIP procedure to clean the milking system took place after each milking. This procedure consisted of a prerinse with water set to reach an initial temperature of $80^{\circ} \mathrm{C}$, an alkaline/ acid rinse, and a postrinse with water. Alkali and acid detergents were alternated for each CIP procedure, and all farms used chlorine-free detergents. However, farm C used a chlorinated alkali disinfectant approximately once a week. In Sweden, chlorinated detergents are not used on dairy farms because of environmental concerns and recommendations from the dairy industry as well as regulations concerning organic certified dairy farms. The cleaning units used were DeLaval C200 and DeLaval C100E (DeLaval). The standardized test procedure devised in the initial work was developed on farm A, and the correlation between ATP and TBC was assessed on farm C.

\section{Measurements of ATP and Total Bacteria Count}

A ready-to-use kit with pre-moistened surface swabs, reagents, and a luminometer from 3M Clean-Trace (3M Svenska AB, Sollentuna, Sweden) was used to obtain swab samples and read the ATP levels, expressed as relative light units (RLU). The predetermined threshold for a clean surface in the study was set at $\leq 150$ RLU, and the fail threshold for a dirty surface was set at $\geq 300$ RLU, based on recommendations. Values from 151 to 299 RLU are accepted, however, indicating that the surface might be deteriorating (Indevex Watertech AB, 2011). The manufacturer of the ATP bioluminescence equipment recommends a surface area of $100 \mathrm{~cm}^{2}$ for swabbing (3M, 2012). It was not possible to obtain such a large surface area in this study, due to the size and shape of the liner and tube and the fact that the test procedure required equipment to remain intact.

Total bacteria count was estimated in parallel to the ATP measurements using Hygicult TPC slides (Food Diagnostics AB, Gothenburg, Sweden) and swabs premoistened with sterile saline solution. An area on liners barrels of $10 \mathrm{~cm}^{2}$ was used for sampling TBC swabs. During the study, 17 samples for colony-forming units and RLU were taken. Samples were incubated at room temperature for $5 \mathrm{~d}$. The number of colony-forming units on each side of the test slide was counted, and a mean value from both sides of the slide was calculated and used. The results were expressed as colony-forming units per $10 \mathrm{~cm}^{2}$, with a recommended threshold for improperly cleaned surfaces of 45 colonies per $10 \mathrm{~cm}^{2}$ or 5 colonies per $\mathrm{cm}^{2}$ (Hygicult TPC, 2012). 
The same person conducted all sampling throughout the study and surfaces were swabbed for approximately $15 \mathrm{~s}$. The time between swabbing and reading of the results was standardized and was never more than 30 min. Plastic gloves were used and replaced frequently to avoid contamination of swabs or equipment.

Water samples were analyzed using the 3M CleanTrace Water Plus-Total ATP Test. Water samples with less than $100 \mathrm{RLU}$ were considered to have good hygiene quality, and values above 200 RLU were considered to represent poor hygiene quality, based on recommendations (Indevex Watertech AB, 2011).

\section{Data Handling and Statistical Analysis}

The data were analyzed using the statistical software programs "R" (version 3.0.0; R Core Team, 2013) and Microsoft Excel (Microsoft Corporation, Redmond, WA). In development of the standardized test procedure, the average of repeated measurements for the different sampling parameters was computed and Student's $t$-test was applied to test for differences between mean values with a $5 \%$ level of significance. The coefficient of variation was used to assess the reproducibility between measurements. Outlying values were removed from the data set of RLU values in the statistical calculations. An outlying value was defined as a value above the upper inner fence $(\mathrm{Q} 3+1.5 \times$ IQR) and upper outer fence (Q3 + $3 \times \mathrm{IQR})$, based on the third quartile (Q3) and inter-quartile range (IQR). Exceptions were made for outlying values below 100 RLU because low values were not likely to be caused by external contamination. In testing the procedure on-farm, an average RLU value based on repeated measurements was calculated for each sampling occasion. Regression analysis was used to investigate the relationship between cfu and RLU on farm C. For this, $\log _{10}$ transformation of both RLU and colony-forming unit values was used because the distributions of values were skewed with tails extending toward higher values.

\section{RESULTS AND DISCUSSION}

\section{A Standardized Procedure for Hygiene Testing of Rubber Liners and Tubes}

Devising a standardized hygiene test procedure for rubber liners and tubes using ATP bioluminescence, the effects of 4 parameters on ATP levels were evaluated.

Sampling Location. Liners used for 3000 milkings, sampled after use of an acid detergent, showed significant differences in ATP levels depending on sampling
Table 1. Effect of sampling location on liners on ATP bioluminescence (relative light units) ${ }^{1}$

\begin{tabular}{lccc}
\hline & \multicolumn{3}{c}{ Location on liner } \\
\cline { 2 - 4 } Item & $\operatorname{Lip}(\mathrm{n}=7)$ & Head $(\mathrm{n}=7)$ & Barrel $(\mathrm{n}=7)$ \\
\hline Mean $\pm \mathrm{SD}$ & $3,766 \pm 3,092^{\mathrm{a}}$ & $97 \pm 63^{\mathrm{b}}$ & $132 \pm 121^{\mathrm{b}}$ \\
$\mathrm{CV}$ & 0.82 & 0.65 & 0.92 \\
\hline
\end{tabular}

${ }_{\mathrm{a}, \mathrm{b}}$ Means with different superscripts differ significantly $(P<0.01)$.

${ }^{1}$ Liners were sampled after 3,000 milkings and use of an acid detergent. Mean value ( $\mathrm{n}=$ number of replicates), $\mathrm{SD}$, and $\mathrm{CV}$ are shown for replicate samplings of different liners on the same or adjacent milking points.

location. Samples from the lip showed significantly higher ATP levels $(P<0.01)$ than samples taken from the head or barrel (Table 1). In general, large variations were observed in RLU values both within and between sampling locations for the same and adjacent liners and clusters. Similarly, studies by Slaghuis and Wiegersma (1996), Reinemann and Ruegg (2000), and Benfalk et al. (2001) also observed large variation between sampling locations. Possible explanations for this variation in RLU values include differences between the areas of the swabbed surfaces, their cleanability, the amount of water, possible detergent residues remaining on the surface, and physical deterioration of rubber at the specific location. The high RLU values observed for liner lip samples could possibly be explained by the fact that the lip was often wet and in contact with residual dirt remaining in the jetter, which could have caused elevated ATP levels. Another factor that may have contributed to the large variation between samples is the presence of other organic ATP-contributing material [e.g., milk residues (Murphy et al., 1998; Corbitt et al., 2000)].

When studying the effect of sampling location in milk tubes older than $1 \mathrm{yr}$ and after the use of an acid detergent, we found no significant differences. Samples taken from the milk meter side showed values $( \pm \mathrm{SD})$ of $213 \pm 152$ RLU and samples from the cluster side values of $505 \pm 680$ RLU. The more homogeneous shape of the milk tube, limited contact with residual dirt at sampling areas, and large variation between measurements are possible explanations why RLU values did not differ between the 2 locations.

Dry Versus Wet Barrels. Letting barrels dry for 4 $\mathrm{h}$ after the cleaning procedure was expected to reduce the variation between measurements, as water residuals have been suggested to increase variation in ATP measurements (Reinemann and Ruegg, 2000). However, no significant difference was observed in RLU values between barrels that were allowed to dry for $4 \mathrm{~h}$ (149 \pm 136 RLU; CV 0.91) and barrels sampled directly after 


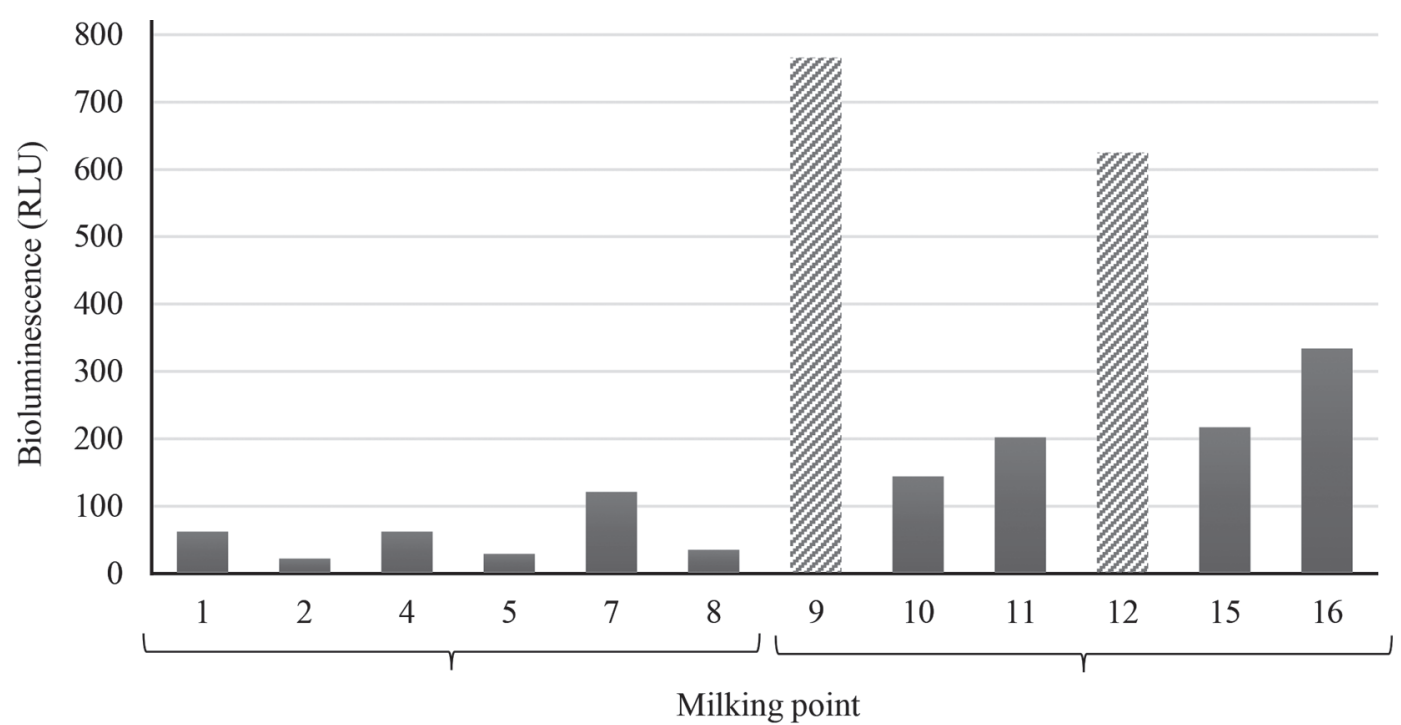

Mean value: 55 RLU

Mean value: 224 RLU

Figure 1. Effect of milking point location on ATP bioluminescence (relative light units, RLU). Milking points 1 to 8 were sampled on the receiver side [i.e., the side where water enters the milking system during the cleaning procedure (clean-in-place, CIP)]. Milking points 9 to 16 were sampled on the opposite side of the milking parlor. Samples were taken from the inside of the liner barrel after 3,000 milkings and use of acid detergent. Cross-hatched columns indicate outlying values that were not included in the statistical calculations. The average RLU values of samples differed significantly $(P<0.01)$ between milking points 1 to 8 and milking points 9 to 16 .

cleaning (132 \pm 121 RLU; CV 0.92). A reason for this could be that the barrel was not very wet despite sampling directly after cleaning.

Milking Point in Parlor. On studying the effect of milking point location and comparing RLU values from liner barrels from the 2 opposite sides of the milking parlor, our results showed a significant difference $(P<$ $0.01)$ between the 2 sides. Samples taken from the side closest to the milk receiver, where the water entered first during the CIP process (milking points 1-8), had a lower mean value than samples from the opposite side of the parlor (Figure 1). These results indicate that there may be differences in cleaning efficiency within the parlor and that the hygiene status at different milking points in a milking parlor may differ. Reinemann and Book (1994) and Reinemann et al. (1997) concluded that the water flow in a milking system can show a large variation between milking units. If the cleaning efficiency at milking units in a milking system differs due to changes in water pressure or uneven distribution of water, this may cause less efficient cleaning and lower the hygiene status of some milking units over time.

Detergent. Samples taken from barrels after use of an acid detergent had significantly lower RLU values $(P<0.01)$ and a larger variation between measurements than samples taken after use of an alkali detergent (Table 2). Other studies have reported that type of detergent affects RLU values when applying ATP bioluminescence in a milking system (Reinemann and
Ruegg, 2000; Pintaric and Pengov, 2007; Vilar et al., 2008). However, those studies do not state whether the effect of acid and alkali detergents on ATP readings was to increase or decrease the RLU values. One explanation for the lower RLU values that we obtained after using an acid detergent could be an effect of detergent residues remaining on the swabbed surface. Omidbakhsh et al. (2014) found that different detergents may have unique effects in either quenching or enhancing ATP readings and that detergent residues thus may have high impacts on ATP readings. This effect was also observed by Velazquez and Feirtag (1997), Green et al. (1998), and Lappalainen et al. (2000). Acid detergents have also been suggested to be more efficient in cleaning a surface (Sundberg et al., 2009). In our study, because we could not conclude whether the lower values obtained after using an acid detergent

Table 2. Effect of type of detergent used in liners on ATP bioluminescence (relative light units) ${ }^{1}$

\begin{tabular}{lcc}
\hline & \multicolumn{2}{c}{ Detergent } \\
\cline { 2 - 3 } Item & Acid $(\mathrm{n}=7)$ & Alkali $(\mathrm{n}=9)$ \\
\hline Mean $\pm \mathrm{SD}$ & $132 \pm 121^{\mathrm{b}}$ & $581 \pm 322^{\mathrm{a}}$ \\
$\mathrm{CV}$ & 0.92 & 0.55 \\
\hline
\end{tabular}

$\overline{\mathrm{a}, \mathrm{b}}$ Means with different superscripts differ significantly $(P<0.01)$.

${ }^{1}$ Mean value ( $\mathrm{n}=$ number of replicates), $\mathrm{SD}$, and $\mathrm{CV}$ are shown for replicate samplings of liners on the same or adjacent milking points after 3,000 milkings. 
were due to more efficient cleaning or were an effect of quenching from detergent residues, sampling after use of an alkali detergent was chosen for the standardized test procedure.

\section{Summary of the Established Test Procedure}

Based on the results obtained on assessing the effect of different sampling parameters on ATP readings, a standardized test procedure for hygiene testing of liners and tubes was devised. For both liners and tubes, it was concluded that in the standardized procedure, several samples should be taken from the same milking points on all sampling occasions at the end of a cleaning procedure using an alkali detergent. It was also concluded that liner sampling should be performed on liners on the inside of the barrel and that for milk tubes samples should preferably be taken from the milk meter side, as the risk of contamination of samples with external dirt on that side is usually lower. The test procedure devised should result in the most reproducible ATP readings, providing a representative picture of the general hygiene status of the milking equipment on-farm.

\section{Hygiene Changes in Liners and Tubes}

The standardized test procedure was applied to investigate the deterioration in hygiene status of aging rubber liners and tubes on dairy farms A, B, and C. The results from each farm are described below.

Farm $\boldsymbol{A}$. On the first sampling occasion after installation (April 14), unexpectedly high values were observed for both liners and tubes despite a successful CIP procedure. Mean values for liners reached 5,453 RLU and for tubes 815 RLU (Figure 2). These high values contradicted evidence of a successful cleaning procedure, as verified by low RLU values at 2 milk meters (196 and 441 RLU, respectively). For comparison, samples from the old, replaced liners taken before dismantling on the same day had a mean value of 581 RLU $(\mathrm{n}=9)$, whereas the old tubes $(>1 \mathrm{yr})$ had a mean value of $169 \mathrm{RLU}(\mathrm{n}=3)$. One possible explanation for the high initial RLU values could be that the new equipment was not subjected to a CIP procedure before being used for the first milking occasion. After installation of new milking equipment, the system should be washed both before and after the first milking, a routine which is recommended by the manufacturer (DeLaval). The high RLU values may thus have been caused by other nonbacterial ATP-contributing material. The milking equipment was re-sampled 8 and 10 $\mathrm{d}$ following installation and the RLU values were much lower on those occasions (Figure 2). During subsequent months, RLU values continued to decrease for both liners and tubes. The tubes showed a similar trend as the liners (i.e., mean RLU values decreased after the initial

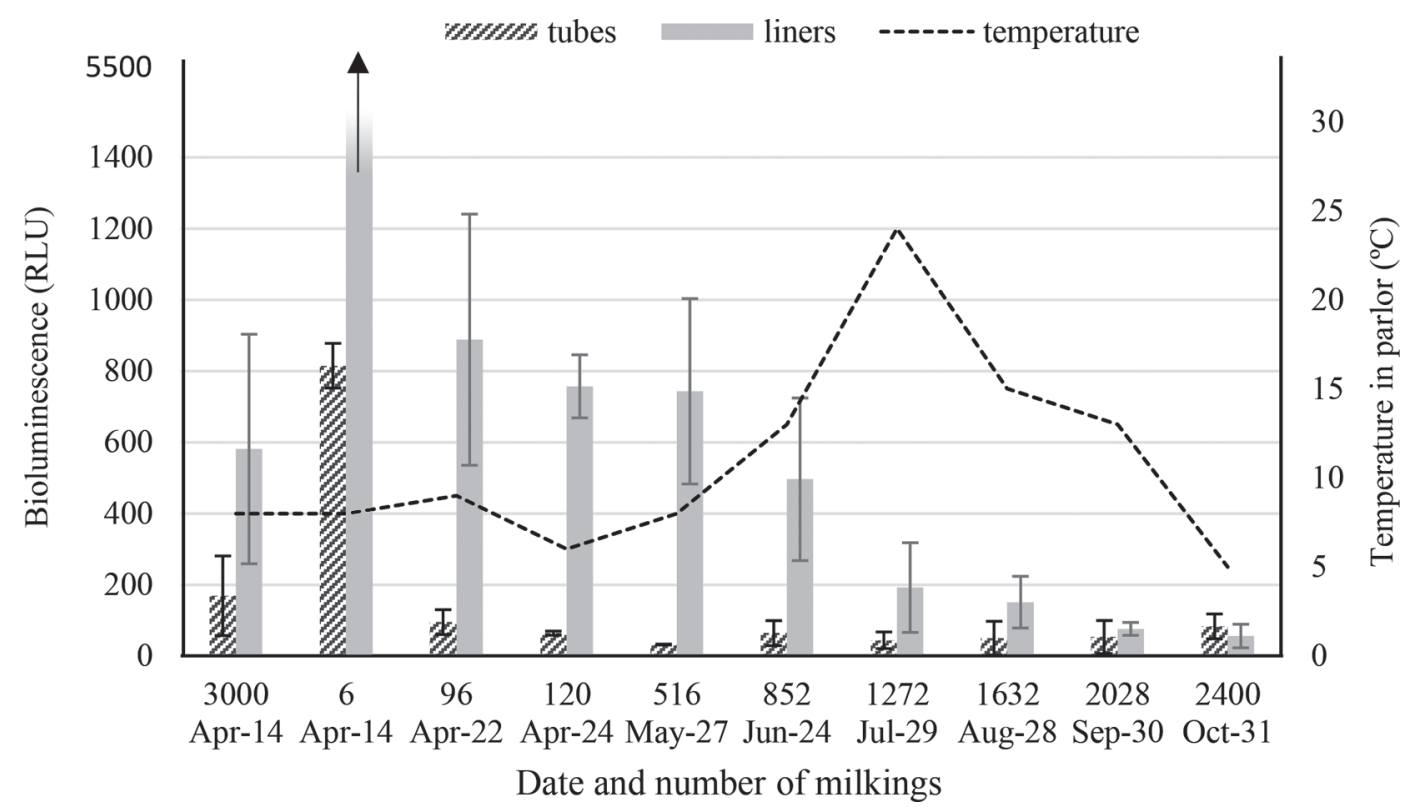

Figure 2. Hygiene status over time of liners and tubes on farm A using ATP bioluminescence (relative light units, RLU). On each sampling occasion, an average RLU value was calculated based on samples taken from the liner barrel $(\mathrm{n}=5-11)$ and from the milk meter side of tubes $(\mathrm{n}=2-5)$ after the use of alkali detergent. Replicates are from the same or adjacent milking points, error bars illustrate \pm SD. Samples taken on April 14, after 3,000 milkings, are from the old set of liners before replacing them. The ambient temperature in the milking parlor is illustrated. The arrow indicates an RLU value of 5,453 . 
high values and then stabilized during the 6 mo of the trial).

Farm B. During the sampling period, average RLU values of liners were initially low (77 RLU, $\mathrm{n}=5$ ) and then increased to reach a mean value of 184 RLU (n $=5$ ) after 1,750 milkings (in July). When the liners had been used for approximately 2,500 milkings, the RLU value decreased again, and continued to decrease throughout the rest of the sampling period except for a slight increase on the last sampling occasion after 4,050 milkings (Figure 3). The trend in tube hygiene was similar to that observed for liners, with an initial peak (in July) and thereafter a decrease that continued throughout the rest of the sampling period except for a slight increase on the last sampling occasion. Season may have had an effect on hygiene, as the highest RLU values were obtained during the peak of summer when the ambient temperature was highest and the cows were out on pasture. In previous studies by Soler et al. (1995), Falkenberg et al. (2005), and Elmoslemany et al. (2010), it was observed that microbial colonization of milking equipment is significantly affected by season. Bacterial numbers are higher in summer than in winter, due to higher ambient temperatures allowing bacteria to multiply faster, especially under conditions of improper cleaning and sanitation of milking equipment.

The low RLU values we obtained on farm B may reflect very efficient cleaning, but may also indicate detergent residues remaining on the swabbed surface, as previously described (Velazquez and Feirtag, 1997;
Lappalainen et al., 2000; Omidbakhsh et al., 2014), or an incorrect swabbing technique. Values below 50 RLU represent normal background levels of ATP according to the manufacturer (3M, 2007). Because the swabbing technique was carefully evaluated during the method development part of the study, it appears unlikely that the low values were caused by an incorrect swabbing technique. Biofilm on a surface can protect ATP from being recovered by the swab, as suggested by Bower et al. (1996) and Bredholt et al. (1999) and later by Pintaric and Pengov (2007). It could therefore be speculated whether low RLU values, such as those obtained on farm B, were caused by biofilm on the surface.

Farm C. Samples from the old liners, used for approximately 3,000 milkings, had a mean value of 24 RLU ( $\mathrm{n}=6)$ after cleaning with alkali detergent. Results for the new liners, installed on May 8, showed a mean value of 67 RLU $(n=5)$. During the next 4 mo and up to 1,620 milkings, the mean value increased up to a peak of $162 \mathrm{RLU}(\mathrm{n}=6)$, which occurred in July. Thereafter, the RLU values decreased again (Figure 4).

Comparison Between Farms. The results for farm $\mathrm{C}$ were very similar to those obtained for farm $\mathrm{B}$, supporting the suggestion that the hygiene level is affected by ambient temperature. Moreover, the results for farms B and C indicated that aging liners can maintain good hygiene quality if the cleaning procedure is efficient. The hygiene level on farm A deviated from that on the other 2 farms. One possible explanation for this is a less efficient cleaning procedure on farm A,

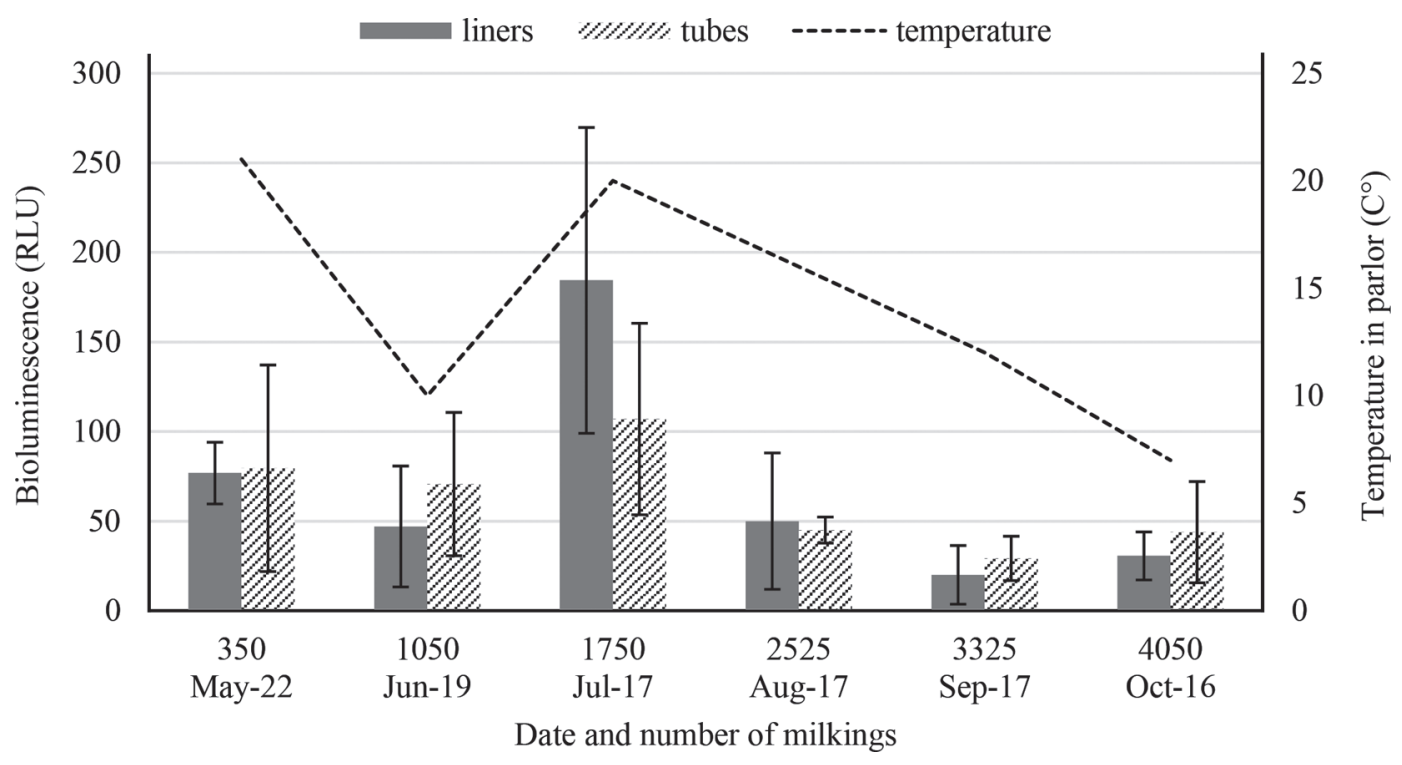

Figure 3. Hygiene status over time of liners and tubes on farm B using ATP bioluminescence (relative light units, RLU). At each sampling occasion, an average RLU value was calculated, based on samples from the liner barrel $(\mathrm{n}=5-7)$ and from the cluster side of tubes $(\mathrm{n}=3-6)$

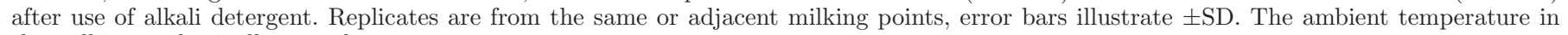
the milking parlor is illustrated. 


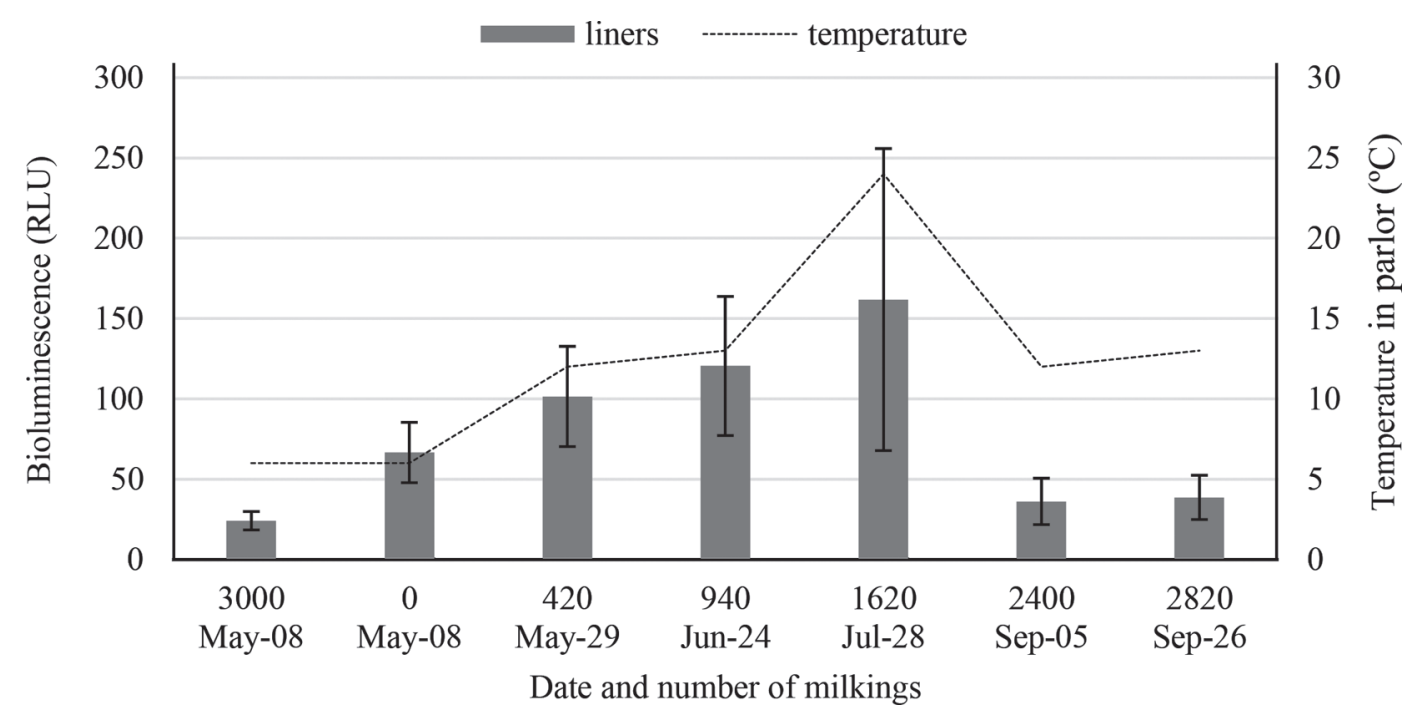

Figure 4. Hygiene status over time of liners on farm C using ATP bioluminescence (relative light units, RLU). At each sampling occasion, an average RLU value was calculated based on samples taken from the liner barrels $(n=5-6)$ on the same or adjacent milking points after use of alkali detergent. Error bars illustrate \pm SD. The samples taken on May 8, after 3,000 milkings, are from the old set of liners that were replaced. The ambient temperature in the milking parlor is illustrated.

with other ATP-contributing material remaining after cleaning, possibly masking an increase in bacterial contamination. The RLU level of the water on the 3 farms varied between 9 and 82 RLU, meeting the requirements for high hygiene quality, and was not considered to have had an effect on the RLU values of the milking equipment.

\section{Correlation Between Colony-Forming Units and RLU}

Our results from sampling 2 barrels of a cluster for both cfu and RLU on farm C during the whole study showed a strong significant correlation $(\mathrm{r}=0.83 ; P<$ 0.0001; Figure 5). This is stronger than the correlation of 0.647 found by Pintaric and Pengov (2007) on studying $\mathrm{TBC}$ and RLU values in a simulated milking system. In comparison, Reinemann and Ruegg (2000) obtained a coefficient of determination $\left(\mathrm{R}^{2}\right)$ of 0.73 when adjacent areas of milking equipment were swabbed. A possible explanation for the strong correlation between colonyforming units and RLU values obtained in our study could be that there was a minimum of other organic debris affecting the ATP levels.

The high correlation between colony-forming units and RLU on farm $\mathrm{C}$ could have been strengthened by the very low RLU values, suggesting a very efficient cleaning procedure. This is in line with Shama and Malik (2013), who stated that high correlations between RLU and colony-forming unit values can be obtained after correction for ATP-contributing material originating from sources other than bacteria. A farm with more organic debris (e.g., milk residues) would probably have a larger discrepancy between colony-forming unit and RLU values. The fact that the samples for determination of colony-forming units and RLU were taken from adjacent areas of the same barrels may also have minimized the variation between samples. On one occasion, after 2,820 milkings, a randomized test was performed and all barrels of a cluster were sampled for both colony-forming units and RLU. One of the barrels showed elevated levels, $591 \mathrm{RLU}$ and $830 \mathrm{cfu}$, whereas the 3 other barrels from the same cluster showed much

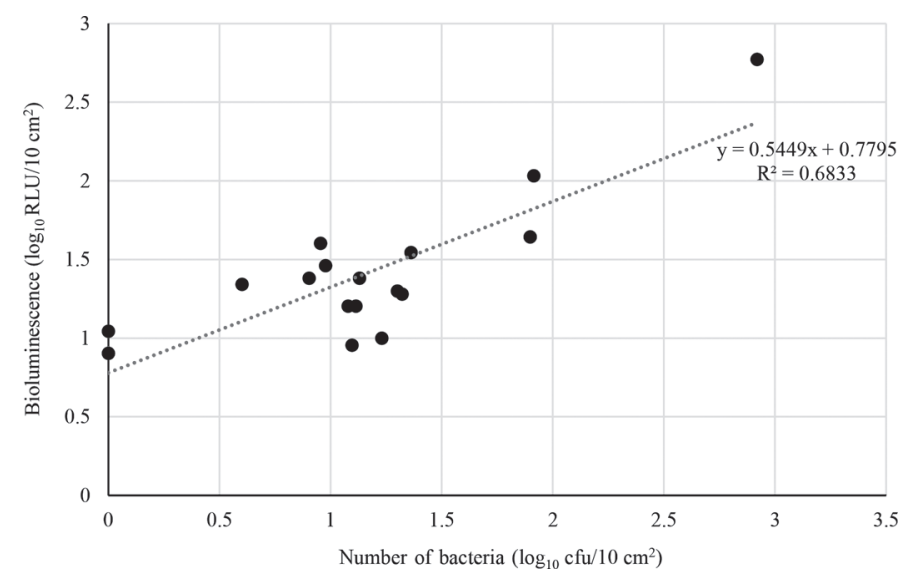

Figure 5. Scatterplot with a fitted regression line between total number of bacteria $\left(\mathrm{cfu}, \mathrm{n}_{\mathrm{cfu}}=17\right)$ and ATP bioluminescence (relative light units, RLU, $\mathrm{n}_{\mathrm{RLU}}=17$ ) on farm C. Regression analysis was performed after $\log _{10}$ transformation of RLU and colony-forming unit values. $P<0.0001$. 
lower levels (i.e., 9, 10, and 16 RLU and 12, 13, and 17 cfu, respectively). This indicates that liners within one cluster can differ significantly with respect to hygiene status, and that it is highly important to take replicate samples when using ATP bioluminescence to assess the hygiene status of milking equipment in the field.

\section{CONCLUSIONS}

To conclude, ATP bioluminescence can be used to follow the hygiene status on farm provided that a standardized procedure for sampling is applied. In case of high RLU values, complementary samples for colonyforming units should be used to find out whether the high values are due to bacteria or other organic ATPcontributing material (e.g., milk residues). Our results indicated that, provided an efficient cleaning procedure, the hygiene quality of milking equipment can be maintained during the recommended lifetime of rubberware.

\section{ACKNOWLEDGMENTS}

The authors thank the participating farms and their staff for their help and for enabling the field tests in this study. This study was performed as an MSc project in collaboration with DeLaval.

\section{REFERENCES}

Aycicek, H., U. Oguz, and K. Karci. 2006. Comparison of results of ATP bioluminescence and traditional hygiene swabbing methods for the determination of surface cleanliness at a hospital kitchen. Int. J. Hyg. Environ. Health 209:203-206.

Bava, L., M. Zucali, A. Sandrucci, M. Brasca, L. Vanoni, L. Zanini, and A. Tamburini. 2011. Effect of cleaning procedure and hygienic condition of milking equipment on bacterial count of bulk tank milk. J. Dairy Res. 78:211-219. https://doi.org/10.1017/ S002202991100001X.

Benfalk, C., K. Lindgren, and C. Jonsson. 2001. ATP-teknik för bestämning av diskningsresultatet i mjölkningsanläggningar. ATP method to determine the cleaning efficiency in milk installations Lantbruk och Industri no 287. JTI- Institutionen för jordbruks och miljöteknik, Uppsala, Sweden.

Boast, D., M. Hale, D. Turner, and J. E. Hillerton. 2008. Variation in rubber chemistry and dynamic mechanical properties of the milking liner barrel with age. J. Dairy Sci. 91:2247-2256. https://doi .org/10.3168/jds.2007-0316.

Bower, C. K., J. McGuire, and M. A. Daeschel. 1996. The adhesion and detachment of bacteria and spores on food-contact surfaces. Trends Food Sci. Technol. 7:152-157.

Bredholt, S., J. Maukonen, K. Kujanpää, T. Alanko, U. Olofson, U. Husmark, and G. Wirtanen. 1999. Microbial methods for assessment of cleaning and disinfection of food-processing surfaces cleaned in a low-pressure system. Eur. Food Res. Technol. 209:145-152. https://doi.org/10.1007/s002170050474.

Corbitt, A. J., N. Bennion, and S. J. Forsythe. 2000. Adenylate kinase amplification of ATP bioluminescence for hygiene monitoring in the food and beverage industry. Lett. Appl. Microbiol. 30:443-447.

Elmoslemany, A. M., G. P. Keefe, I. R. Dohoo, and B. M. Jayarao. 2009. Risk factors for bacteriological quality of bulk tank milk in Prince Edward Island dairy herds. Part 2: Bacteria count-specific risk factors. J. Dairy Sci. 92:2644-2652. https://doi.org/10.3168/ jds.2008-1813.

Elmoslemany, A. M., G. P. Keefe, I. R. Dohoo, J. J. Wichtel, H. Stryhn, and R. T. Dingwell. 2010. The association between bulk tank milk analysis for raw milk quality and on-farm management practices. Prev. Vet. Med. 95:32-40. https://doi.org/10.1016/j .prevetmed.2010.03.007.

Falkenberg, U., P. Reinhold, G. Hildebrandt, and W. Heuwieser. 2005. Development of microbiological colonisation in a newly installed milking system. Pages 171-176 in Physiological and Technical Aspects of Machine Milking. ICAR Technical Series, No. 10. Nitra, Slovak Republic. M. ICAR, Villa del Ragno, Rome, Italy.

Green, T. A., S. M. Russel, and D. L. Fletcher. 1998. Effect of chemical sanitizing agents on ATP bioluminescence measurements. J. Food Prot. 61:1013-1017.

Griffiths, M. W. 1993. Applications of bioluminescence in the dairy industry. J. Dairy Sci. 76:3118-3125. https://doi.org/10.3168/jds S0022-0302(93)77651-1.

Hillerton, J. E., D. Boast, N. Middleton, and I. Ohnstad. 2004. Changes in milking liner performance with age. Pages 35-40 in 100 Years with Liners and Pulsators in Machine Milking. IDF Bulletin No. 388, International Dairy Federation, Brussels, Belgium.

Hygicult TPC. 2012. Instructions for use. Orion Diagnostica Oy, Espoo, Finland.

Indevex Watertech AB. 2011. 3M ${ }^{\mathrm{TM}}$ Clean-Trace ${ }^{\mathrm{TM}}$, Snabb och säker hygienkontroll. Accessed Apr. 12, 2014. https://iwab.se/20.0.0.0/ 1293/36e04f0e90c60f9e0abb414bf439427b.pdf.

Lappalainen, J., S. Loikkanen, M. Havana, M. Karp, A. M. Sjöberg, and G. Wirtanen. 2000. Microbial testing methods for detection of residual cleaning agents and disinfectants- prevention of ATP bioluminescence measurement errors in the food industry. J. Food Prot. 63:210-215. https://doi.org/10.4315/0362-028X-63.2.210.

Latorre, A. A., J. S. Van Kessel, J. S. Karns, M. J. Zurakowski, A. K. Pradhan, K. J. Boor, and Y. H. Schukken. 2010. Biofilm in milking equipment on a dairy farm as a potential source of bulk tank milk contamination with Listeria monocytogenes. J. Dairy Sci. 93:2792-2802. https://doi.org/10.3168/jds.2009-2717.

Meyer, M. J., and K. A. Schmidt. 1997. ATP bioluminescence can evaluate cleaning and sanitizing effectiveness in the milking parlor. Pages 47-50 in Dairy Day 1997, Conference Paper. Kansas Agricultural Experiment Station and Cooperative Extension Service.

Murphy, S. C., S. M. Kozlowski, D. K. Bandler, and K. J. Boor. 1998. Evaluation of adenosin triphosphate-bioluminescence hygiene monitoring for troubleshooting fluid milk shelf-life problems. J. Dairy Sci. 81:817-820. https://doi.org/10.3168/jds.S0022 -0302(98)75639-5.

Omidbakhsh, N., F. Ahmadpour, and N. Kenny. 2014. How reliable are ATP bioluminescence meters in assessing decontamination of environmental surfaces in healthcare settings? PLoS One 9:e99951. https://doi.org/10.1371/journal.pone.0099951.

Pintaric, S., and A. Pengov. 2007. Use of quick diagnostic methods in milking. Int. J. Environ. Pollut. 31:167-177. https://doi.org/10 .1504/IJEP.2007.015673.

R Core Team. 2013. R: A language and environment for statistical computing. R Foundation for Statistical Computing, Vienna, Austria. http://www.R-project.org.

Reinemann, D. J., and J. M. Book. 1994. Airflow requirements, design parameters and troubleshooting for cleaning milking systems. Pages 26-35 in Proc. ASAE/NMC Dairy Housing Conference No 31. Orlando, FL.

Reinemann, D. J., R. W. Peebles, and G. A. Mein. 1997. Control strategies for milking parlor clean in-place systems. Trans. ASAE 40:1749-1753. https://doi.org/10.13031/2013.21407.

Reinemann, D. J., and P. L. Ruegg. 2000. An investigation of ATP bioluminescence and quantitative bulk tank cultures to assess cleanliness of milking machines. Pages 10-13 in Paper No. 003009. ASAE Ann. Int. Meet., Milwaukee, WI. American Society of Agricultural Engineers, St. Joseph, MI.

Reinemann, D. J., G. M. V. H. Wolters, P. Billon, O. Lind, and M. D. Rasmussen. 2003. Review of Practices for Cleaning and Sanitation of Milking Machines. Bull. 381. Int. Dairy Fed., Brussels, Belgium. 
Shama, G., and D. J. Malik. 2013. The uses and abuses of rapid bioluminescence-based ATP assays. Int. J. Hyg. Environ. Health 216:115-125. https://doi.org/10.1016/j.ijheh.2012.03.009.

Slaghuis, B., and W. Wiegersma. 1996. Use of ATP-technique for the control of the cleaning of milking equipment. Pages 173-174 in Proc. IDF Symposium on Bacteriological Quality of Raw Milk. Austria, 13-15 March. International Dairy Federation, Brussels, Belgium.

Soler, A., C. Ponsell, M. De Paz, and M. Nunez. 1995. The microbiological quality of milk produced in the Balearic Islands. Int. Dairy J. 5:69-74. https://doi.org/10.1016/0958-6946(94)P1599-9.

Storgards, E., H. Simola, A. M. Sjöberg, and G. Wirtanen. 1999. Hygiene of gasket materials used in food processing equipment part 2: Aged materials. Food Bioprod. Process. 77:146-155. https://doi .org/10.1205/096030899532295.

Sundberg, M., C. Lindahl, A. Christiansson, and C. Birgersson. 2009. Klorfria diskmedel för gårdsdisk-studier av olika faktorers inverkan på diskresultatet. Chlorine free detergents for use on dairy farms: Study of the influence of different factors on cleaning effectiveness. JTI-Institutet för jordbruks och miljöteknik, Uppsala, Sweden.

Teh, K. H., S. Flint, J. Palmer, P. Andrewes, P. Bremer, and D. Lindsay. 2014. Biofilm-An unrecognised source of spoilage enzymes in dairy products? Int. Dairy J. 34:32-40. https://doi.org/10.1016/k idairyj.2013.07.002.

Teixeira, P., Z. Lopes, J. Azeredo, R. Oliveira, and M. J. Vieira. 2005. Physico-chemical surface characterization of a bacterial population isolated from a milking machine. Food Microbiol. 22:247-251.

3M. 2007. The $3 \mathrm{M}^{\mathrm{TM}}$ Clean-Trace ${ }^{\mathrm{TM}}$ Hygiene Management Guide. 3M Health Care. St. Paul, MN

3M. 2012. Product Instructions UXL 100. 3M Health Care, St. Paul, $\mathrm{MN}$.

Velazquez, M., and J. M. Feirtag. 1997. Quenching and enhancement effects of ATP extractants, cleansers, and sanitizers on the detection of the ATP bioluminescence signal. J. Food Prot. 60:799-803. https://doi.org/10.4315/0362-028X-60.7.799.

Verdier-Metz, I., V. Michel, C. Delbes, and M. C. Montel. 2009. Do milking practices influence the bacterial diversity of raw milk? Food Microbiol. 26:305-310. https://doi.org/10.1016/j.fm.2008.12 .005 .

Vilar, M. J., J. L. Rodríguez-Otero, F. J. Diéguez, M. L. Sanjuán, and E. Yus. 2008. Application of ATP bioluminescence for evaluation of surface cleanliness of milking equipment. Int. J. Food Microbiol. 125:357-361. https://doi.org/10.1016/j.ijfoodmicro.2008.04.024. 